\title{
Prevention of unintended pregnancies in Nigeria; the effect of socio- demographic characteristic on the knowledge and use of emergency contraceptives among female university students
}

\author{
Olumide A. Abiodun ${ }^{1}$, John Sotunsa ${ }^{2}$, Olusoji Jagun ${ }^{3}$, Bukola Faturoti ${ }^{4}$, \\ Franklin Ani' ${ }^{2}$ Imaralu John², Agboola Taiwo ${ }^{5}$, Ogechukwu Taiwo ${ }^{4}$
}

\begin{abstract}
${ }^{1}$ Department of Community Medicine, Benjamin Carson (Snr) College of Medicine, Babcock University, Ilishan, Nigeria

${ }^{2}$ Department of Obstetrics \& Gynecology, Benjamin Carson (Snr) College of Medicine, Babcock University, Ilishan, Nigeria

${ }^{3}$ Department of Obstetrics \& Gynecology, Obafemi Awolowo College of Health Sciences, Olabisi Onabanjo University, Sagamu, Nigeria

${ }^{4}$ Department of Paediatric Surgery, Benjamin Carson (Snr) College of Medicine, Babcock University, Ilishan, Nigeria ${ }^{5}$ Department of Orthopaedic Surgery, Benjamin Carson (Snr) College of Medicine, Babcock University, Ilishan, Nigeria
\end{abstract}

Received: 06 April 2015

Accepted: 09 May 2015

\section{*Correspondence:}

Dr. Olumide A. Abiodun,

E-mail: olumiabiodun@gmail.com

Copyright: ( $)$ the author(s), publisher and licensee Medip Academy. This is an open-access article distributed under the terms of the Creative Commons Attribution Non-Commercial License, which permits unrestricted non-commercial use, distribution, and reproduction in any medium, provided the original work is properly cited.

\footnotetext{
ABSTRACT

Background: The proportion of unintended pregnancy remains high in developing regions due to unmet need for contraception and inconsistent use of modern contraceptives. Practice of emergency contraception is particularly important because of the high rates of unintended pregnancy. The aim was to assess the practice of emergency contraception among female students.

Methods: A cross-sectional study was conducted among 5,233 female university students in Nigeria.

Results: About $25.4 \%$ of the students had ever had sex while $64.3 \%$ had heard about emergency contraceptives. About half (49.6\%) had good knowledge while $70 \%$ thought that emergency contraceptives are effective and easy to access and use. Good knowledge about emergency contraceptives was predicted by dwelling urban or suburban areas $(\mathrm{AOR}=1.750$ and 1.817; $\mathrm{P}<0.05)$, being single $(\mathrm{AOR}=2.597, \mathrm{P}=0.001)$, being in the fourth year $(\mathrm{AOR}=2.096$, $\mathrm{P}<0.001)$ and having ever had sex $(\mathrm{AOR}=1.449, \mathrm{P}<0.001)$. Having ever used emergency contraceptive is predicted by good knowledge $(\mathrm{AOR}=1.852, \mathrm{P}<0.001)$ and perception that emergency contraceptives are effective $(\mathrm{AOR}=139.774$, $\mathrm{P}<0.001)$ and easy to access and use $(\mathrm{AOR}=8.429, \mathrm{P}<0.001)$.

Conclusions: Despite a significant risk of unintended pregnancy among female university students, the usage rate of emergency contraceptive is very low. There is a need to actively promote emergency contraception along with other contraceptive methods with the involvement of health workers and the media.
}

Keywords: Emergency contraceptive, Female students, Unintended pregnancy 


\section{INTRODUCTION}

Unintended pregnancy and the consequences of attending unsafe abortion are major causes of maternal morbidity and mortality. Despite a drop in global rates of pregnancy and unintended pregnancy, the proportion of unintended pregnancies remains high in developing regions including Nigeria. ${ }^{1,2}$ Nearly $90 \%$ of the estimated 208 million pregnancies in the year 2008 occurred in developing countries. Globally, 86 million pregnancies were unintended; of these, 41 million ended in abortion, 33 million in unplanned birth and 11 million in miscarriages. ${ }^{1}$ Africa has the highest rate of intended (136 per 1000) and unintended pregnancies (86 per 1000) worldwide. ${ }^{1}$ The incidence of unintended pregnancy is quite high (90 per 1000) in Nigeria with many of the women turning to abortion to avoid unwanted births. ${ }^{3,4}$ Unintended pregnancy constitutes a major problem at the community level in Nigeria. The global variations in levels of unintended pregnancy may be explained by unmet need for contraception, incorrect and inconsistent use of modern contraceptives.

Studies across sub-Saharan Africa show that women who tend to have induced non-medical abortion are below the age of 30 years and are literate; many of whom being above the secondary educational level, usually undergraduates. ${ }^{5-7}$ Women seeking abortion as a result of unwanted pregnancy in southwest Nigeria are mostly aged between 15 and 24 years, unmarried and predominantly students of higher institution. ${ }^{8}$

In Nigeria emergency contraceptives are available as combined oral contraceptive pills, progestin only oral contraceptives (E-pills) and Copper $\mathrm{T}$ Intra Uterine Devices (IUDs). The COCPs are about $75 \%$ effective and contain both oestrogen and progesterone. The E-pills contain levonorgestrel, are the most commonly used and are about $95 \%$ effective. Available brands include Postinor2, Pregnon, Smart lady, Ecee2 and Truston. The tablets should be taken as soon possible after unprotected intercourse but within 120 hours and then repeated after 12 hours. If the Cupper T IUDs are inserted as soon as possible but within 7 days of unprotected sexual intercourse, they prevent over $99 \%$ of unintended pregnancies. IUDs are not commonly used method of emergency contraception in Nigeria. In Nigeria, emergency contraceptive pills are readily available over the counter and in health facilities at affordable rates.

Emergency contraceptives are especially vital to unmarried couples who do not use regular contraceptive methods because their sexual behavior is unplanned, erratic and irregular. ${ }^{9}$ It is also useful in cases of rape or coerced sex. However, it is not a substitute for and is often not as effective as long term contraceptives and should be restricted only to use after unprotected sexual intercourse.
Studies show that the knowledge and use of emergency contraceptives are limited among women in sub-Saharan Africa despite the high rates of the unintended pregnancies. $^{9-11}$ In spite of the utility of emergency contraceptives in preventing unintended pregnancy, studies reveal poor perception and uptake among Nigerian undergraduates. ${ }^{12-14}$

Nigerian studies among undergraduate students have exclusively been carried out in Public higher institutions. To the best of our knowledge, there are no such studies in private universities despite more than fifty of such that are scattered all over the country, with many thousands of female students. The aim of this study is therefore to assess the level of knowledge, perception and use of emergency contraceptives among female undergraduate students at a privately run university in south west Nigeria.

\section{METHODS}

\section{Study setting and sample}

A cross-sectional study was conducted among female students at Babcock University, Ilishan Nigeria between September 2013 and January 2014. Babcock University is one of the 51 private universities in Nigeria. The study population is all female undergraduate students of Babcock University. The University is one of the first three private universities in Nigeria and about the biggest with many of the other private universities modelled after it. The University has total of about 9955 regular undergraduate students. Information obtained from the University registry showed that there were 5744 female students enrolled for undergraduate programs across 8 schools and one college of health and medical sciences. This constituted $57.7 \%$ of undergraduate student population.

\section{Sample size and sampling procedure}

Total Sampling was done. All female undergraduate students of Babcock University, Ilishan, Nigeria were therefore eligible to participate in the study. However, only those consented participated in the study. Questionnaire administration was done during the monthly fellowship meetings which is compulsory for all students.

\section{Measurement and definition of variables}

All the female students of Babcock University as at September, 2013 were eligible to participate in the survey. Data was collected with the use of selfadministered questionnaires. The self-administered questionnaire used contained 40 questions on sociodemographic factors, knowledge, perception and practice of emergency contraception. The questionnaire was adapted from a similar study in Addis Ababa, Ethiopia. ${ }^{9}$ Some modifications were made to suit the study context. 
Three Reproductive Health Specialists were requested to vet the instrument and establish content validity. The Specialists made various suggestions which were taken into account, and necessary corrections were made. There was consensus among the Specialists on the suitability of the instrument for use in the study context. Stability and reliability of the questionnaire was assessed by the testretest reliability method which was carried out among 50 female undergraduate students in a public university; two weeks apart $(\mathrm{r}=0.8)$. The questionnaire was then pretested among 600 female students at a Public University in Nigeria. Necessary adjustments were made.

\section{Independent variables}

Age was dichotomized and coded as $\leq 19$ ('younger') and $>19$ ('older'). The age range of the participants was between 15 and 42 years. The median and modal ages were 19 years, which was used as the cut-off point. Place of residence was categorized as rural, urban or sub-urban.

Religious affiliation was dichotomized into Christianity, Islam and others.

Marital status was dichotomized into single (single, never married) and not single (ever married).

Monthly allowance was categorized into three namely 5000 to 10000 Naira, >10000 to 20000 and >20000 Naira (1 US Dollars is equivalent to about 160 Naira). The year (level) of study of the participants were recorded as $100 \mathrm{~L}$ (first year), 200L (second year), 300L (third year), 400L (fourth year) and 500L (fifth year).

Awareness referred to whether the participant had heard about emergency contraception before.

Knowledge about EC was assessed using a number of questions which included:

1. Choosing correctly the forms of emergency contraceptives from a list

2. Identifying correctly that emergency contraceptives is required after unintended unprotected sexual intercourse to avoid pregnancy

3. The timing of use of each emergency contraceptive method relative to sexual activity

4. The frequency of dosing of emergency contraceptives.

The knowledge questions consist of a total of 23 questions. Each correct answer is given a score of one while a wrong answer is given a score of zero. The scores of each of the participants were then added up and graded over a maximum of 23 . The knowledge scores were then dichotomized into 'poor knowledge' $(\leq 11)$ and 'good knowledge' $(>11)$. The mean and median knowledge scores were 10.85 and 11 respectively. The median score was used as the cut-off point.

The perception of effectiveness and ease of access and use of emergency contraceptive pills with one question each requiring 'Yes' or 'No' answers. 'Yes' implied that the participant thought that ECs were effective at preventing pregnancy and that ECs were easy to use. Ease of use refers to access and actual use of emergency contraception. Knowledge and perception of emergency contraception were only assessed among those who were aware of emergency contraception.

\section{Dependent variable}

Uptake and non-uptake of EC was assessed by the question: Have you ever used any method to avoid pregnancy after having unprotected sexual intercourse? Participants were expected to respond either 'Yes' or 'No'.

\section{Statistical analysis}

Data processing and analysis was done using the SPSSv17 for windows program. Descriptive statistics and odds ratio, with $95 \%$ confidence interval were used to show associations between target variables.

\section{Ethical issues}

Ethical clearance and permission was obtained from the Babcock University Teaching Hospital Ethical Committee. Informed verbal consent was obtained from each participant. Prior to the administration of questionnaire, the purpose of the study was explained to the participants. The students were free to decline participation in the study. Confidentiality was maintained by omitting their personally identifiable information such as names from the questionnaire.

\section{RESULTS}

Consent and full response was obtained from 5233 female students giving a response rate of $91.1 \%$. The high response rate is attributable to the fact that it was easy to have access to all the students because survey was carried out during the monthly fellowship meeting which was compulsory for all students. The investigators made special efforts to obtain the consent $t$ of the students and relevant university authorities. The mean age of participants was $19.17 \pm 2.27$ years. Majority $(73.6 \%)$ of the students were aged between 15 and 19 years; while $21.9 \%$ were between 20 and 24 years old. About a quarter $(25.4 \%)$ reported that they had ever had sex. Among those who were sexually active, about $52.0 \%$ have had at least one episode of unprotected in the preceding six months. As shown in Table 1, 55.3\% of them were less than or equal to 19 years old, $83.5 \%$ of them live in urban settings. Majority of the respondents were Christians $(87.8 \%)$. Only $83(1.6 \%)$ of the students were not single. 
Table 1: Socio-demographic and academic characteristics of female undergraduate students in Ilishan, Nigeria, January 2014.

\begin{tabular}{|c|c|c|c|c|c|}
\hline \multirow{3}{*}{ Variables } & \multirow{3}{*}{$\mathrm{n}=5233(\%)$} & \multicolumn{2}{|l|}{ Ever had sex } & \multirow{3}{*}{$x^{2}$} & \multirow{3}{*}{ P value } \\
\hline & & Yes & No & & \\
\hline & & $\mathrm{n}=1328(\%)$ & $\mathrm{n}=3905(\%)$ & & \\
\hline \multicolumn{6}{|l|}{ Age } \\
\hline$\leq 19$ years & $2893(55.3)$ & $555(19.2)$ & $2338(80.8)$ & \multirow{2}{*}{131.037} & \multirow{2}{*}{$<0.0001^{\wedge}$} \\
\hline$>19$ years & $2340(44.7)$ & $773(33.0)$ & $1567(67.0)$ & & \\
\hline \multicolumn{6}{|c|}{ Place of residence } \\
\hline Rural & $354(6.8)$ & $178(50.3)$ & $176(49.7)$ & \multirow{3}{*}{153.026} & \multirow{3}{*}{$<0.0001^{\wedge}$} \\
\hline Suburban & $510(9.7)$ & $170(33.3)$ & $340(66.7)$ & & \\
\hline Urban & $4369(83.5)$ & $980(22.4)$ & $3389(77.6)$ & & \\
\hline \multicolumn{6}{|l|}{ Marital status } \\
\hline Single & $5150(98.4)$ & $1253(24.3)$ & $3897(75.7)$ & 188.069 & \multirow{2}{*}{$<0.0001^{\wedge}$} \\
\hline Not single & $83(1.6)$ & $75(90.4)$ & $8(9.6)$ & & \\
\hline \multicolumn{6}{|l|}{ Year of study } \\
\hline $100 \mathrm{~L}$ & $2117(40.5)$ & $264(12.5)$ & $1853(87.5)$ & \multirow{5}{*}{559.884} & \multirow{5}{*}{$<0.0001^{\wedge}$} \\
\hline $200 \mathrm{~L}$ & $1392(26.6)$ & $316(22.7)$ & $1076(77.3)$ & & \\
\hline $300 \mathrm{~L}$ & $858(16.4)$ & $330(38.5)$ & $528(61.5)$ & & \\
\hline $400 \mathrm{~L}$ & $659(12.6)$ & $279(42.3)$ & $380(57.7)$ & & \\
\hline $500 \mathrm{~L}$ & $207(4.0)$ & $139(67.1)$ & $68(32.9)$ & & \\
\hline \multicolumn{6}{|l|}{ Religion } \\
\hline Christianity & $4594(87.8)$ & $1049(22.8)$ & $3545(77.2)$ & 333.018 & $<0.0001^{\wedge}$ \\
\hline Islam & $465(8.9)$ & $133(28.6)$ & $332(71.4)$ & & \\
\hline Others & $174(3.3)$ & $146(83.9)$ & $28(16.1)$ & & \\
\hline \multicolumn{6}{|c|}{ Average monthly allowance (Naira)* } \\
\hline $5000-10000$ & $2338(45.4)$ & $482(20.6)$ & $1856(79.4)$ & \multirow{3}{*}{99.279} & \multirow{3}{*}{$<0.0001^{\wedge}$} \\
\hline$>10000-20000$ & $1925(37.4)$ & $493(25.6)$ & $1432(74.4)$ & & \\
\hline$>20000$ & $882(17.1)$ & $333(37.8)$ & $549(62.2)$ & & \\
\hline
\end{tabular}

*There were 88 (1.7\%) missing values which were excluded from analysis

${ }^{\wedge}$ Statistically significant at $\mathrm{P}<0.05$

Table 2: Knowledge, perception and practice of emergency contraception among female undergraduate students in Ilishan, Nigeria, January 2014.

\begin{tabular}{|c|c|c|c|c|c|}
\hline \multirow{3}{*}{ Variables } & \multirow{3}{*}{ n $(\%)$} & \multicolumn{2}{|c|}{ Ever had sex } & \multirow{3}{*}{$x^{2}$} & \multirow{3}{*}{ P value } \\
\hline & & Yes & No & & \\
\hline & & n $(\%)$ & n $(\%)$ & & \\
\hline \multicolumn{6}{|c|}{ Awareness of emergency contraception } \\
\hline Yes & $3365(64.3)$ & $964(28.6)$ & $2401(71.4)$ & 53.242 & \multirow{2}{*}{$<0.001^{\wedge}$} \\
\hline No & $1868(35.7)$ & $364(19.5)$ & $1504(80.5)$ & & \\
\hline \multicolumn{6}{|c|}{ Knowledge of emergency contraception* } \\
\hline good knowledge & $1668(49.6)$ & $540(32.4)$ & $1128(67.6)$ & 22.467 & \multirow{2}{*}{$<0.001^{\wedge}$} \\
\hline poor knowledge & $1697(50.4)$ & $424(25.0)$ & $1273(75.0)$ & & \\
\hline \multicolumn{6}{|c|}{ Perception of effectiveness of emergency contraception* } \\
\hline Effective & $2520(74.9)$ & $719(28.5)$ & $1801(71.5)$ & 0.066 & \multirow{2}{*}{0.797} \\
\hline Not effective & $845(25.1)$ & $245(29.0)$ & $600(71.0)$ & & \\
\hline \multicolumn{6}{|c|}{ Perception of ease of uptake of emergency contraception* } \\
\hline Easy to use EC & $2423(72.0)$ & $698(28.8)$ & $1725(71.2)$ & 0.108 & \multirow{2}{*}{0.743} \\
\hline Not easy to use EC & $942(28.0)$ & $266(28.2)$ & $676(71.8)$ & & \\
\hline
\end{tabular}

*Measured only among participants who were aware of emergency contraception ${ }^{\wedge}$ Statistically significant at $\mathrm{P}<0.05$ 
Table 1 also demonstrates statistically significant association between having ever had sex certain sociodemographic characteristics including age, place of residence, marital status, year of study, religion and average monthly allowances $(\mathrm{P}<0.05)$.

Table 2 highlights the awareness, knowledge, perception and uptake of emergency contraception. Among the participants, 3365 (64.3\%) were aware of emergency contraception. The major sources of information about emergency contraceptives were friends (28.2\%), the media $(24.9 \%)$ and parents $(16.0 \%)$. Only $10.5 \%$ and $7.2 \%$ of respondents got information from hospital and schools respectively.

The mean knowledge score was 10.85 with standard deviation of 5.81 and median score of 11.00. The scores ranged from 0 to 23 . Among participants who were aware of emergency contraceptives, 1668 (49.6\%) had good knowledge while 1697 (50.4\%) had poor knowledge. More than $70 \%$ of the participants who were aware of emergency contraceptives thought that it was effective $(74.9 \%)$ and easy to access and use (72.0\%). However, only $718(13.7 \%)$ of all the participants had ever used emergency contraception. Of these, $82.5 \%$ used Progestin only pills while $17.5 \%$ used combined oral contraceptive pills. None used IUDs. The main sources of emergency contraceptives were partners $(46.0 \%)$ and medicine stores $(35.3 \%)$. Other sources included friends (10.1\%) and health workers $(8.0 \%)$.

Table 2 also shows that having ever had sex was statistically related to awareness, knowledge and uptake of emergency contraception $(\mathrm{P}<0.05)$ but was not related to the participants' perception of the effectiveness and ease of use of EC $(\mathrm{P}>0.05)$.

Table 3: Predictors of good knowledge about emergency contraception among female undergraduate students in Ilishan, Nigeria, January 2014.

\begin{tabular}{|c|c|c|c|c|}
\hline \multirow{2}{*}{ Variables } & \multicolumn{4}{|c|}{ Knowledge of emergency contraception } \\
\hline & Coefficient $(\beta)$ & SE & P value & AOR (95\% CI) \\
\hline \multicolumn{5}{|l|}{ Age } \\
\hline \multicolumn{5}{|l|}{$\leq 19$ years } \\
\hline$>19$ years & 0.060 & 0.076 & 0.428 & $1.062(0.915-1.233)$ \\
\hline \multicolumn{5}{|c|}{ Place of residence } \\
\hline Urban & 0.560 & 0.157 & $<0.001$ & $1.750(1.286-2.383) *$ \\
\hline Suburban & 0.597 & 0.187 & 0.001 & $1.817(1.259-2.622)^{*}$ \\
\hline \multicolumn{5}{|l|}{ Rural } \\
\hline \multicolumn{5}{|l|}{ Marital status } \\
\hline Single & 0.954 & 0.300 & 0.001 & $2.597(1.442-4.677)^{*}$ \\
\hline \multicolumn{5}{|l|}{ Not single } \\
\hline \multicolumn{5}{|l|}{ Year of study } \\
\hline $100 \mathrm{~L}$ & 0.145 & 0.193 & 0.453 & $1.156(0.792-1.688)$ \\
\hline $200 \mathrm{~L}$ & 0.019 & 0.194 & 0.922 & $1.019(0.697-1.490)$ \\
\hline $300 \mathrm{~L}$ & 0.194 & 0.197 & 0.325 & $1.214(0.825-1.784)$ \\
\hline $400 \mathrm{~L}$ & 0.740 & 0.199 & $<0.001$ & $2.096(1.418-3.099)^{*}$ \\
\hline \multicolumn{5}{|l|}{$500 \mathrm{~L}$} \\
\hline \multicolumn{5}{|l|}{ Religion } \\
\hline Christianity & 0.177 & 0.236 & 0.453 & $1.194(0.752-1.896)$ \\
\hline Islam & 0.491 & 0.264 & 0.063 & $1.635(0.974-2.742)$ \\
\hline \multicolumn{5}{|l|}{ Others } \\
\hline \multicolumn{5}{|c|}{ Average monthly allowance (Naira) } \\
\hline $5,000-10000$ & -0.297 & 0.100 & 0.003 & $0.743(0.610-0.910)^{*}$ \\
\hline$>10000-20000$ & -0.223 & 0.104 & 0.031 & $0.800(0.653-0.980)^{*}$ \\
\hline \multicolumn{5}{|l|}{$>20000$} \\
\hline \multicolumn{5}{|l|}{ Ever had sex } \\
\hline Yes & 0.371 & 0.086 & $<0.001$ & $1.449(1.224-1.715)^{*}$ \\
\hline No & & & & \\
\hline
\end{tabular}

*Statistically significant at $\mathrm{P}<0.05$ 
Table 3 presents the result of multinomial logistic regression of knowledge about emergency contraceptives (dependent variable) and socio-demographic characteristics of participants who were aware of EC. Good knowledge about emergency contraceptives was predicted by place of residence, marital status, being in four hundred level, average monthly allowance and having ever had sex $(\mathrm{P}<0.05)$. Participants living in the urban and suburban areas were more likely to have good knowledge of EC than those from the rural areas $(\mathrm{AOR}=1.750$ and 1.817 respectively). Single participants were more likely to have good knowledge about emergency contraceptives than those that were not (AOR=2.597, $\mathrm{P}=0.001$ ). Participants in four hundred level were twice as likely to have good knowledge about emergency contraceptives as those in five hundred level (AOR=2.096, $\mathrm{P}<0.001)$. Participants whose monthly allowances were less than or equal to twenty thousand Naira were less likely to have good knowledge about emergency contraceptives than those whose allowances were more than twenty thousand Naira monthly. Participants who had ever had sex were more likely to have good knowledge about emergency contraceptives than those who had not $(\mathrm{AOR}=1.449, \mathrm{p}<0.001)$.

Table 4: Predictors of perception about emergency contraception among female undergraduate students in Ilishan, Nigeria, January.

\begin{tabular}{|c|c|c|c|c|c|c|}
\hline \multirow{2}{*}{ Variables } & \multicolumn{3}{|c|}{ Effectiveness of emergency contraception } & \multicolumn{3}{|c|}{ Ease of uptake of emergency contraception } \\
\hline & Coefficient ( $\beta)$ & P value & $\operatorname{AOR}(95 \% \mathrm{CI})$ & Coefficient ( $\beta)$ & P value & $\operatorname{AOR}(95 \% \mathrm{CI})$ \\
\hline \multicolumn{7}{|l|}{ Age } \\
\hline$\leq 19$ years & 0.022 & 0.800 & $1.022(0.862-1.213)$ & 0.007 & 0.937 & $1.007(0.853-1.188)$ \\
\hline \multicolumn{7}{|l|}{$>19$ years } \\
\hline \multicolumn{7}{|l|}{ Place of residence } \\
\hline Urban & 0.131 & 0.456 & $1.140(0.808-1.609)$ & 0.226 & 0.181 & $1.253(0.900-1.744)$ \\
\hline Suburban & 0.288 & 0.179 & $1.334(0.876-2.031)$ & -0.092 & 0.645 & $0.912(0.617-1.349)$ \\
\hline \multicolumn{7}{|l|}{ Rural } \\
\hline \multicolumn{7}{|l|}{ Marital status } \\
\hline Single & 0.876 & 0.005 & $2.402(1.297-4.446)^{*}$ & 0.443 & 0.156 & $1.588(0.845-2.872)$ \\
\hline \multicolumn{7}{|l|}{ Not single } \\
\hline \multicolumn{7}{|l|}{ Year of study } \\
\hline $100 \mathrm{~L}$ & -0.588 & 0.014 & $0.555(0.347-0.888)^{*}$ & -0.959 & $<0.001$ & $0.383(0.242-0.608)^{*}$ \\
\hline $200 \mathrm{~L}$ & -0.313 & 0.192 & $0.731(0.457-1.170)$ & -0.63 & 0.008 & $0.533(0.335-0.846)^{*}$ \\
\hline $300 \mathrm{~L}$ & 0.007 & 0.978 & $1.007(0.621-1.632)$ & -0.219 & 0.367 & $0.803(0.500-1.292)$ \\
\hline $400 \mathrm{~L}$ & 0.075 & 0.763 & $1.078(0.661-1.758)$ & -0.135 & 0.581 & $0.874(0.540-1.412)$ \\
\hline \multicolumn{7}{|l|}{$500 \mathrm{~L}$} \\
\hline \multicolumn{7}{|l|}{ Religion } \\
\hline Christianity & -0.893 & 0.006 & $0.409(0.216-0.774)$ & -0.153 & 0.573 & $0.858(0.504-1.462)$ \\
\hline Islam & -1.077 & 0.002 & $0.341(0.172-0.674)$ & -0.726 & 0.014 & $0.484(0.271-0.863)^{*}$ \\
\hline \multicolumn{7}{|l|}{ Others } \\
\hline \multicolumn{7}{|c|}{ Average monthly allowance (Naira) } \\
\hline $5000-10000$ & -0.482 & $<0.001$ & $0.618(0.487-0.783)^{*}$ & -0.123 & 0.275 & $0.884(0.708-1.103)$ \\
\hline$>10000-20000$ & -0.263 & 0.036 & $0.769(0.601-0.983)^{*}$ & -0.03 & 0.797 & $0.970(0.772-1.220)$ \\
\hline \multicolumn{7}{|l|}{$>20000$} \\
\hline \multicolumn{7}{|l|}{ Ever had sex } \\
\hline Yes & -0.267 & 0.007 & $0.766(0.632-0.928)^{*}$ & -0.151 & 0.117 & $0.860(0.713-1.038)$ \\
\hline \multicolumn{7}{|c|}{ No } \\
\hline \multicolumn{7}{|c|}{ Knowledge of emergency contraception } \\
\hline Good knowledge & -0.156 & 0.058 & $0.856(0.728-1.005)$ & -0.125 & 0.116 & $0.882(0.754-1.032)$ \\
\hline Poor knowledge & & & & & & \\
\hline
\end{tabular}

*Statistically significant at $\mathrm{P}<0.05$

Table 4 presents the result of multinomial logistic regression of perception about effectiveness and ease of use of EC (dependent variables) and socio-demographic characteristics of participants. The perception that emergency contraceptives are effective was predicted by being single $(\mathrm{AOR}=2.402, \mathrm{P}=0.005)$, monthly allowances 
being greater than twenty thousand Naira and having never had sex $(\mathrm{P}<0.05)$. Also participants in $100 \mathrm{~L}$ were less likely to think that emergency contraceptives are effective than those in 500L. Participants in $100 \mathrm{~L}$ $(\mathrm{AOR}=0.383, \mathrm{P}<0.001)$ and $200 \mathrm{~L}(\mathrm{AOR}=0.533, \mathrm{P}=0.008)$ were less likely to think that about emergency contraceptives are easy to use compared to those in 500L. Participants who were Muslims were less likely to think that emergency contraceptives are easy to use than those who practiced religions other than Christianity (AOR=0.484, $\mathrm{P}<0.0014)$.

Table 5: Predictors of uptake of emergency contraception among female undergraduate students in Ilishan, Nigeria, January 2014.

\begin{tabular}{|c|c|c|c|c|}
\hline \multirow{2}{*}{ Variables } & \multicolumn{4}{|c|}{ Ever used emergency contraception } \\
\hline & Coefficient $(\beta)$ & SE & $P$ value & AOR (95\% CI) \\
\hline \multicolumn{5}{|l|}{ Age } \\
\hline$\leq 19$ years & -0.256 & 0.111 & 0.020 & $0.774(0.623-0.961)^{*}$ \\
\hline \multicolumn{5}{|l|}{$>19$ years } \\
\hline \multicolumn{5}{|l|}{ Place of residence } \\
\hline Urban & -0.967 & 0.211 & $<0.001$ & $0.380(0.252-0.574)^{*}$ \\
\hline Sub-Urban & -0.419 & 0.249 & 0.093 & $0.658(0.403-1.072)$ \\
\hline \multicolumn{5}{|l|}{ Rural } \\
\hline \multicolumn{5}{|l|}{ Marital status } \\
\hline Single & -1.472 & 0.402 & $<0.001$ & $0.229(0.104-0.504)^{*}$ \\
\hline \multicolumn{5}{|l|}{ Not single } \\
\hline \multicolumn{5}{|l|}{ Level of study } \\
\hline $100 \mathrm{~L}$ & -1.664 & 0.241 & $<0.001$ & $0.189(0.118-0.304)^{*}$ \\
\hline $200 \mathrm{~L}$ & -1.057 & 0.235 & $<0.001$ & $0.348(0.219-0.551)^{*}$ \\
\hline $300 \mathrm{~L}$ & -0.183 & 0.233 & 0.431 & $0.833(0.528-1.313)$ \\
\hline $400 \mathrm{~L}$ & -0.104 & 0.237 & 0.661 & $0.901(0.566-1.435)$ \\
\hline \multicolumn{5}{|l|}{$500 \mathrm{~L}$} \\
\hline \multicolumn{5}{|l|}{ Religion } \\
\hline Christianity & -1.988 & 0.325 & $<0.001$ & $0.137(0.072-0.259)^{*}$ \\
\hline Islam & -1.978 & 0.367 & $<0.001$ & $0.138(0.067-0.284)^{*}$ \\
\hline \multicolumn{5}{|l|}{ Others } \\
\hline \multicolumn{5}{|c|}{ Average monthly allowance (Naira) } \\
\hline $5,000-10000$ & -0.826 & 0.134 & $<0.001$ & $0.438(0.336-0.570)^{*}$ \\
\hline$>10000-20000$ & -0.609 & 0.137 & $<0.001$ & $0.544(0.416-0.711)^{*}$ \\
\hline \multicolumn{5}{|l|}{$>20000$} \\
\hline \multicolumn{5}{|c|}{ Knowledge of emergency contraception } \\
\hline Good knowledge & 0.616 & 0.105 & $<0.001$ & $1.852(1.506-2.276)^{*}$ \\
\hline \multicolumn{5}{|c|}{ Poor knowledge } \\
\hline \multicolumn{5}{|c|}{ Perception of effectiveness of emergency contraception } \\
\hline Effective & 4.940 & 0.327 & $<0.001$ & $139.774(73.647-265.278)^{*}$ \\
\hline \multicolumn{5}{|c|}{ Not effective } \\
\hline \multicolumn{5}{|c|}{ Perception of ease of uptake of emergency contraception } \\
\hline Easy to use EC & 2.132 & 0.166 & $<0.001$ & $8.429(6.092-11.662)^{*}$ \\
\hline Not easy to use EC & & & & \\
\hline
\end{tabular}

*Statistically significant at $\mathrm{P}<0.05$

Table 5 presents the result of multinomial logistic regression of having ever used an emergency contraceptive (dependent variables) and sociodemographic characteristics of participants. Participants who were 19 years and less were less likely to have used emergency contraceptives $(\mathrm{AOR}=0.774, \mathrm{P}=0.020)$. Urban dwellers were also less likely to have used emergency contraceptives than rural dwellers (AOR $=0.380$, $\mathrm{P}<0.001)$. Single participants were less likely to have used emergency contraceptives than those who were not $(\mathrm{AOR}=0.229, \mathrm{P}<0.001)$. Students in 100 and 200 levels were less likely to have used emergency contraceptive 
than the more senior students $(\mathrm{P}<0.001)$. Christians and Muslims were less likely to have used emergency contraceptives than the other students $(\mathrm{P}<0.001)$. Participants whose monthly allowances were less than or equal to twenty thousand Naira were less likely to have used emergency contraceptives than those whose allowances were more than twenty thousand Naira $(\mathrm{P}<0.001)$. Use of emergency contraceptives was also predicted by good knowledge $(\mathrm{AOR}=1.852, \mathrm{P}<0.001)$, perception that they are effective $(\mathrm{AOR}=139.774$, $\mathrm{P}<0.001)$ and perception that they are easy to access and use $\quad(\mathrm{AOR}=8.429, \quad \mathrm{P}<0.001)$. Perceptions about emergency contraceptives were by far the most potent predictor of use.

\section{DISCUSSION}

This study investigated the sexual activity and knowledge, perception as well as use of emergency contraceptives among female university students in Nigeria. The study demonstrated that about a quarter of the students were sexually active, $52 \%$ of these having being involved in unprotected sexual intercourse in the preceding six months. It also showed that $64.3 \%$ were aware of emergency contraceptives while only $13.7 \%$ had ever used any form of emergency contraceptive (either combined or progestin only pills). Among those who were aware of emergency contraceptives, about half had good knowledge about it while more than $70 \%$ perceived that emergency contraceptives were effective and easy to access and use. Having ever had sex was associated with Age ( $>19$ years), place of residence (rural), marital status (not being single), level of study (more senior students), religion (others apart from Christianity and Islam), monthly allowances (higher than 20000 Naira), awareness of and good knowledge about emergency contraceptives. Good knowledge about emergency contraceptives is predicted by residence in urban or suburban setting, being single, being in the fourth year, having a monthly allowance that is higher than 20000 Naira and having ever had sex.

Having ever used emergency contraceptive is predicted by age ( $>19$ years), residence in rural area, not being single, being in 300 level and above, others religion apart from Christianity and Islam, monthly allowances higher than 20000 Naira, good knowledge about emergency contraceptives and perceptions that emergency contraceptives are effective and easy to use.

Certain shortfalls of this study should be put into consideration when interpreting the findings. The study was cross-sectional in design hence, causality cannot be established. The relatively large number of participants in this study however mitigated the effect of this factor. The use of self-reported data is prone to a number of biases that could affect the reliability and validity of a measure. There could be recall biases and self-presentation or confidentiality concerns resulting from stigmatization. This is further underlined by the fact that the study was conducted in a Faith based university where Christian values are an integral part of learning. This was however mitigated by assuring participants of full confidentiality, completion of questionnaire in private and by making data collection a simple self-administered process.

The study was conducted in only one private university. This will limit the generalizability of the findings to the entire population of private university students in Nigeria. The university is one of the three oldest private universities and about the biggest in Nigeria. Many of the other private universities are modelled after it by being largely residential as opposed to public universities which are largely non-residential in Nigeria. Despite these shortcomings, this study fills a gap in research in the area Sexual activity and use of emergency contraceptives. Total sampling was used and the sample size was considerable.

The proportion of students who had ever had sex in this study is similar to studies of female university students in Ethiopia ${ }^{9}$ but quite low compared with other studies in Uganda and Tanzania and South Africa. ${ }^{15-17}$ Studies conducted among general university students' population in Nigeria also showed higher rates of sexual activity. ${ }^{18}$ The proportion is however higher than those conducted among female secondary school students. ${ }^{19}$ This is probably related to the ages of the students. The mean age of the students in our study is lower than that of the similar studies but higher than those among female secondary school students. Besides, the students live in a full boarded university where they are monitored closely unlike public universities where students live by themselves and are free to do as they will.

The level of awareness about emergency contraceptives in this study is similar or higher than in studies conducted in higher institutes in other parts of Nigeria, Ethiopia, South Africa, Ghana, and other developing countries reported more or less similar findings. $9,10,20,21$

The prevalence of good knowledge of students about EC was significantly higher compare to similar studies in Cameroon, Ghana and Kenya. ${ }^{21-23}$ South Korean students have also shown a general lack of knowledge about emergency contraceptives and with a lot of misconceptions about their effectiveness. ${ }^{24}$ The knowledge about emergency contraceptives seems to be on the rise among young people globally and specifically in sub-Saharan Africa.

Achieving universal awareness and widespread high knowledge about emergency contraceptives has been challenging because it is not quite promoted and readily made available in health institution and by health providers. This would explain why majority of participants in this study got information about emergency contraceptives from other sources. It has also been argued that promoting emergency contraceptives will hinder the efforts to promote other forms of contraception especially among young people, though some evidences have contradicted this. ${ }^{25}$ 
High proportion of the students thought that emergency contraceptives were effective and quite easy to access and use. This contrasts a similar study in Ethiopia where considerable proportions of university students reported misconceptions about emergency contraceptives. ${ }^{9}$ However, this study like ours found positive perceptions to be significantly higher among senior students than junior ones.

Our findings showed that emergency contraceptive use rate was comparable to the finding in Ethiopia ${ }^{9}$ but lower than those of other studies in Nigeria and South Africa. $^{20,21}$ This difference could be related to the proportion of sexually active students which is similar to that in the Ethiopian study and much lower than the others. The major source of emergency contraceptives is similar to other studies. ${ }^{7}$ The predictors of emergency contraception use as determined by this study are similar to the findings in Uganda. ${ }^{26}$ A study in the United States of America also identified moral acceptability and ease of obtaining emergency contraceptives as potent predictors of use. ${ }^{27}$ This study has provided important baseline information regarding emergency contraceptives among female university students. It also provides insight to program managers on how and to whom educational message on contraception should be targeted.

The difference between emergency contraceptive usage and sexual risk behaviour exposes high proportion of the young women to the risk of unintended pregnancy and sexually transmitted infections as a sizeable proportion of the participants in this study were not using contraception despite the prevalence of unprotected sexual intercourse. There is evidence for the promotion of emergency contraceptives alongside regular contraception and this should be commenced as early feasible in adolescence before the onset of sexual activity. ${ }^{25}$ Education campaigns and extensive social marketing of contraceptive commodities in response to HIV epidemic has been reported to be very effective..$^{28,29}$ There is need to adopt similar approach in promoting EC in order to increase its use. Monitoring and mentorship of women may be justifiable as this study has shown that the female students in a fully boarded university might be less involved in sexual activities than their colleagues who are not.

Despite the fact that the majority of the students obtain contraceptive services from the shops, it has been showed that students would prefer to get contraceptive services from the health facilities. ${ }^{7}$ This underscores the need to for health institutions (including the university health centres) and health care providers to actively promote emergency contraceptive use and to make the commodities readily available. It is also pertinent to have for relevant information in shops, pharmacies and the media. The messages on emergency contraceptives must specifically promote the perceptions that emergency contraceptives have some level of effectiveness and can be easily accessed and used since this study has found this to be the most potent predictor of use of EC.
Consequently, efforts must be made to actually ensure the availability and continued affordability of the commodities.

Interestingly, while the urban dwelling and single students were more knowledgeable about emergency contraceptives, it was the rural dwelling and not single students who were using them. It is therefore pertinent that more information about emergency contraceptives and their effectiveness should be provided for rural dwellers. The knowledge of urban dwellers should be reenforced with information on the use and availability of emergency contraception.

Future research should explore behavioural predictors of use of EC and the barrier to the use of EC in this and similar population.

\section{CONCLUSION}

The study demonstrates that despite a significant risk of unintended pregnancy among female university students, the practice on emergency contraceptive is very low. There is a need to actively promote EC along with other contraception methods with the involvement of health workers and the media. Adolescent girls need to have access to quality family life education program as early as it is feasible.

\section{ACKNOWLEDGEMENTS}

We would like to thank our research assistants who worked tirelessly towards the success of this study. We thank the officials at the university registry for their help in providing official data. Our gratitude also goes to students who willingly participated in the study.

\section{Funding: No funding sources}

Conflict of interest: None declared

Ethical approval: The study was approved by the Babcock University Teaching Hospital ethics committee

\section{REFERENCES}

1. Kott A. Rates of unintended pregnancy remain high in developing regions. Int Fam Plann Perspect. 2011;37(1):46-7.

2. Sigh S, Sedgh G, Hussain R. Unintended pregnancy: Worldwide levels, trends and outcomes. Stud Fam Plann. 2010;41(4):241-50.

3. Sedgh G, Bankole A, Oye-Adeniran B, Adewole IF, Singh S, Hussain R. Unintended pregnancy and associated factors among Nigerian women. Int Fam Plann Perspect. 2006;32(4):175-84.

4. Oye-Adeniran BA, Adewole IF, Umoh AV, Ekanem EE, Gbadegesin A, Iwere N. Community-based survey of unwanted pregnancy in South-Western Nigeria. Afri J Reprod Health. 2004;8(3):103-15.

5. Melkamu Y, Enquselassie F, Ali A, Gebresilassie H, Yusuf L. Fertility awareness and future pregnancy 
intention of post abortion patients in Addis Ababa, Ethiopia. Ethiop J Health Devel. 2003;17(3):167-74.

6. Cadmus EO, Owoaje ET. Knowledge about complications and practice of abortion among female undergraduates in the University of Ibadan, Nigeria. Ann Ibadan Postgrad Med. 2011;9(1):19-23.

7. Somba MJ, Mbonile M, Obure Joseph, Mahande MJ. Sexual behavior, contraceptive knowledge and use among female undergraduates' students of Muhimbili and Dar es Salaam Universities, Tanzania: a cross-sectional study. BMC Women's Health. 2014;14:94.

8. Oye-Adeniran BA, Adewole IF, Umoh AV, Fapohunda OR, Iwere N. Characteristics of abortion seekers in south-western Nigeria. Afr $\mathbf{J}$ Reprod Health. 2004;8(3):81-91.

9. Wagene T, Fikre E. Knowledge, attitude, and practice on emergency contraceptives among female university students in Addis Ababa, Ethiopia. Ethiop J Health Devel. 2007;21(2):111-6.

10. Robert C, Moodley J, Esterhuizen T. Emergency contraception: Knowledge and practice of tertiary students in Durban, South Africa. J Obstet Gynaecol. 2004 Jun;24(4):441-5.

11. Aziken ME, Okonta PI, Ande AB. Knowledge and perception of emergency contraception among female Nigerian undergraduates. Int Fam Plann Perspect. 2003 Jun;29(2):84-7.

12. Nworah JAO, Mbamarah US, Ugboaja OJ, Ogelle OM, Akabuile CJ. Knowledge, attitude and practice of emergency contraception among students in tertiary schools in Anambra State Southeast Nigeria. Int J Med Med Sci. 2010;2(1):1-4.

13. Ikeme AC, Ezegwui HU, Uzodinma AC. Knowledge, attitude and use of emergency contraception among female undergraduates in Eastern Nigeria. J Obstet Gynecol. 2005;25(5):491-3.

14. Bello FA, Olayemi O, Fawole AO, Ogunbode OO, Sobukunola T, Adeshina OA, et al. Perception and Practice of emergency contraception among female undergraduates of the University of Ibadan, Nigeria. J Reprod Contracept. 2009;20(2):N113-21.

15. Agardh A, Tumwine G, Östergren P-O. The impact of socio-demographic and religious factors upon sexual behavior among Ugandan University students. PLoS One. 2011;6(8):e23670.

16. Somba MJ, Mbonile M, Obure J, Mahande MJ. Sexual behaviour, contraceptive knowledge and use among female undergraduates' students of Muhimbili and Dar es Salaam Universities, Tanzania: a cross-sectional study. BMC Women's Health. 2014;14:94.

17. Hoque ME, Ghuman S, Van Hal G. Human Papillomavirus vaccination acceptability among female University students in South Africa. Asian Pac J Cancer Prev. 2013;14(8):4865-9.
18. Tobin-West CI, Maduka O, Onyekwere VN, Tella AO. Awareness, acceptability, and use of female condoms among university students in Nigeria: implications for STI/HIV prevention. Int J Adolesc Med Health. 2014;26(2):259-65.

19. Melaku YA, Berhane Y, Kinsman J, Reda HL. Sexual and reproductive health communication and awareness of contraceptive methods among secondary school female students, northern Ethiopia: a cross-sectional study. BMC Public Health. 2014;14:252.

20. Arowojolu AO, Adekunle AO. Perception and practice of EC by post-secondary students in South West Nigeria. Afr J Reprod Health. 2000;4(1):56-65.

21. Baiden F, Awini E, Clerk C. Perception of university students in Ghana about EC. Contraception. 2002;66(1):23-6.

22. Kongnyuy EJ, Ngassa P, Fomulu N, Wiysonge CS, Kouam L, Doh AS. A survey of knowledge, attitudes and practice of emergency contraception among university students in Cameroon. BMC Emerg Med. 2007;7:7.

23. Muia E, Ellertson C, Lukhando M, Flul B, Clark S, Olenja J. Emergency Contraception in Nairobi, Kenya: knowledge, attitudes and practices among policy makers, family planning providers and Clients, and university students. Contraception. 1999;60:223-32.

24. Kang HS, Moneyham L. Use of emergency contraceptive pills and condoms by college students: a survey. Int J Nurs Stud. 2008 May;45(5):775-83.

25. Jackson RA, Schwarz EB, Freedman L, Darney P. Advance supply of emergency contraception: Effect on use of usual contraception. Obstet Gynaecol. 2001;102(1):8-16.

26. Mehra D, Agardh A, Petterson KO, Ostergren PO. Non-use of contraception: determinants among Ugandan university students. Glob Health Action. 2012;5:18599.

27. Fitzpartrick V, Mouttapa M, Tanjasiri SP, Napoli J. Predictors of women's emergency contraception use and men's support of partner's use among college students. Californ J Health Promot. 2014;12(2):7889.

28. Akani CI, Enyindah CE, Babatunde S. Emergency contraception: knowledge and perception of female undergraduates in the Niger delta of Nigeria. Ghana Med J. 2008;42(2):68-70.

29. Ebuehi OM, Ekanem EE, Ebuehi OA. Knowledge and practice of emergency contraception among female undergraduates in the University of Lagos, Nigeria. East Afr Med J. 2006;83(3):90-5.

DOI: $10.18203 / 2320-1770 . i j r \operatorname{cog} 20150087$

Cite this article as: Abiodun OA, Sotunsa J, Jagun O, Faturoti B, Ani F, John I, Taiwo A, Taiwo O. Prevention of unintended pregnancies in Nigeria; the effect of socio-demographic characteristic on the knowledge and use of emergency contraceptives among female university students. Int J Reprod Contracept Obstet Gynecol 2015;4:755-64. 